\title{
ANALISIS PEMBERDAYAAN MASYARAKAT DESA DALAM KEMANDIRIAN DAN PEMBANGUNAN DI KECAMATAN JAMBI LUAR KOTA
}

\author{
Nopyandri ${ }^{1}$, A Zarkasi ${ }^{2}$, Dimas Rizal ${ }^{3}$ \\ ${ }^{1,2}$ Fakultas Hukum, Universitas Jambi, ${ }^{3}$ Ilmu Politik, Universitas \\ Jambi \\ 1№pyandri22@gmail.com ${ }^{2}$ zarkasi.unja@gmail.com \\ dimas_rizalcr7@yahoo.com
}

\begin{abstract}
The purpose of this study was to determine the role of the village government of Jambi luar kota in empowering rural communities in rural independence and development. As we know, The Village autonomy is genuine, round, and complete autonomy and is not a gift from the government. Instead, the government is obliged to respect the original autonomy held by the village. As a form of democracy, a village consultative body was formed in the village which functioned as a legislative and supervisory body for the implementation of village regulations, village income and expenditure budgets, and village head decisions. The village budget includes original village income, APBN allocation known as the Village Fund, part of the district/city revenue and tax, village fund allocation which is part of the balance funds received by the district/city, financial assistance from the provincial $A P B D$ and district / APBD cities, grants and non-binding donations from third parties. With so many funds for village development above, can the village government implement an independent village development and support the village development program launched by the central government or vice versa. This study was conducted using a qualitative research approach. This research was conducted in Jambi Luar Kota and in Muaro Jambi Regency. The results of this study found that the empowerment of Village Communities in SelfReliance and Development in Jambi Luar Kota District even though it has been done, the results are not yet optimal. it is due to several factors: 1). Communication Factors, 2). Organizational structure.
\end{abstract}

Keywords: Autonomy, Villages, Community Empowerment, Development. 


\section{A. PENDAHULUAN}

Otonomi daerah adalah kewenangan daerah otonom untuk mengatur dan mengurus kepentingan masyarakat setempat menurut prakarsa sendiri berdasarkan aspirasi masyarakat, sesuai dengan peraturan per-undangundangan (Widjaja, 2011 : 76). Pelaksanaan otonomi daerah saat ini lebih berfokus pada pemberian kewenangan yang besar kepada daerah untuk mengatur dan mengurus rumah tangganya sendiri dalam mengelola pembangunan daerah menuju otonomi daerah dalam kerangka Negara Kesatuan Republik Indonesia. Otonomi daerah sendiri bertitik berat pada tingkat kabupaten/kota, namun jika dilihat senyatanya otonomi daerah ini didasarkan atas kemandirian dari penyelenggaraan pemerintahan yang paling bawah yaitu desa. Oleh sebab itu, yang menjadi fokus utama pada pembangunan daerah yaitu membangun desa. UU Nomor 23 Tahun 2014 menjelaskan bahwa, Otonomi Daerah adalah wewenang, hak, serta kewajiban pemerintah daerah untuk mengurus serta mengatur urusannya sendiri guna untuk kepentingan masyarakat dalam sistem NKRI. Otonomi daerah bertujuan meningkatkan efektifitas dan efisiensi dalam perumusan dan pembuatan kebijakan oleh daerah. Karena daerah dianggap yang paling tahu persoalan yang dihadapi oleh masyarakatnya serta bertujuan untuk memberikan pelayanan prima kepada masyarakat.

Prinsip dalam peleksanaan otonomi daerah ialah keadilan serta demokratisasi, memperhatikan keanekaragaman dan potensi daerah, kesesuaian antara pemerintah pusat dan daerah, meningkatkan kemandirian daerah yang utuh dan luas kepada kabupaten/kota. Kebijaksanaan terbatas pada daerah propinsi serta desa ditempatkan pada pengakuan otonomi asli (HAW Widjaja, 2005 : 1-2).

Selain otonomi daerah, Indonesia juga menganut otonomi desa yang merupakan otonomi yang asli, bulat dan utuh. Secara historis desa merupakan cikal bakal terbentuknya masyarakat politik dan pemerintahan di indonesia jauh sebelum negara bangsa ini terbentuk. Struktur sosial sejenis desa, masyarakat adat dan lain sebagainya telah menjadi institusi sosial yang 
Jurnal SOSIO DIALEKTIKA 5 (2) (2020)

P-ISSN: 2540.8941 e-ISSN: 2623.2944

sosiodialektika@unwahas.ac.id
Analisis Pemberdayaan

Masyarakat Desa Dalam

Kemandirian Dan

Pembangunan Di Kecamatan

Jambi Luar Kota

mempunyai posisi yang sangat penting. Desa merupakan institusi yang otonom dengan tradisi, adat istiadat dan hukumnya sendiri serta relatif mandiri. Hal ini antara lain ditunjjukkan dengan tingkat keragaman yang tinggi membuat desa mungkin merupakan wujud bangsa yang paling kongkret (HAW Widjaja, 2005:4). Dalam UU Republik Indonesia No 6 Tahun 2014 Tentang Desa dijelaskan bahwa desa adalah desa dan desa adat atau yang disebut dengan nama lain, selanjutnya disebut desa, adalah kesatuan masyarakat hukum yang memiliki batas wilayah yang berwenang untuk mengatur dan mengurus urusan pemerintahan, kepentingan masyarakat setempat berdasarkan prakarsa masyarakat, hak asal usul, dan/ atau hak tradisional yang diakui dan dihormati dalam sistem pemerintahan Negara Kesatuan Republik Indonesia.

Pemahaman mengenai Desa di atas menunjukkan bahwa Desa merupakan suatu organisasi terkecil dalam suatu Negara yang terletak relatif jauh dari kota dan mayoritas penduduknya bercorak agraris. Desa menurut Sutarjo Kartohadikusumo merupakan kesatuan hukum tempat tinggal suatu masyarakat yang berhak menyelenggarakan rumah tangganya sendiri merupakan pemerintahan terendah di bawah camat (Saibani dan Djati H, 2014 : 233). Desa menjadi faktor yang paling utama dalam tercapainya suatu program yang dicanangkan oleh Pemerintah dan dapat dikatakan bahwa dengan penyelenggaraan otonomi desa dan kewenangan desa menjadi prioritas utama dalam pembangunan nasional yang tugasnya dilimpahkan kepada Pemerintah Desa. Sejalan dengan hal tersebut, menurut survei penduduk jumlah sebaran penduduk Indonesia sampai dengan awal tahun 2015, tercatat sebanyak 45\% (112,5\% juta jiwa) dari total jumlah penduduk Indonesia tinggal di desa. Maka dapat dikatakan bahwa desa menjadi pondasi dasar dalam terciptanya pembangunan nasional.

Undang-Undang Nomor 6 Tahun 2014 Tentang Desa juga mengatur keuangan desa dan aset desa dalam rangka memberikan pelayanan pada masyarakat antara lain dari sumber-sumber Pendapatan Desa, adanya kewajiban bagi Pemerintah dari pusat sampai pada Kabupaten atau Kota 
untuk memberikan transfer dana bagi desa, hibah ataupun donasi. Menurut Indra Bastian ( 2015 : 20), keuangan desa adalah konsekuensi dari adanya urusan pemerintahan yang diserahkan kepada desa. Adanya sumber keuangan yang memadai memungkinkan desa untuk melaksanakan tugas dan fungsi desa.

Sumber pendapatan desa berdasarkan Pasal 72 Undang-Undang Nomor 6 Tahun 2014 Tentang Desa bersumber dari pendapatan Asli Desa atas hasil usaha, hasil asset, swadaya dan partisipasi, gotong-royong, dan lain-lain pendapatan asli desa; alokasi Anggaran Pendapatan dan Belanja Negara; bagian dari hasil pajak daerah dan retribusi daerah Kabupaten/Kota; alokasi dana desa yang merupakan bagian dari dana perimbang-an yang diterima Kabupaten/Kota; bantuan keuangan dari Anggaran Pendapatan dan Belanja Daerah Provinsi dan Anggaran Pendapatan dan Belanja Daerah Kabupaten /Kota; hibah dan sumbangan yang tidak mengikat dari pihak ketiga; dan lain-lain pendapatan Desa yang sah.

Dalam upaya meningkatkan kemandirian masyarakat desa maka dibutuhkan keuangan desa. Dalam UU Nomor 6 Tahun 2014 Tentang Desa pasal 71 dijelaskan, Keuangan desa merupakan kewajiban dan hak desa yang bisa dinilai berupa uang dan semua sesuatu dengan uang serta barang yang berkaitan dengan pelaksanaan kewajiban dan hak desa. Adapun anggaran desa meliputi pendapatan asli desa, alokasi APBN yang dikenal dengan Dana Desa, bagian dari hasil dan pajak daerah kabupaten/kota, alokasi dana desa yang merupakan bagian dari dana perimbangan yang diterima kabupaten/kota, bantuan keuangan dari APBD provinsi dan APBD kabupaten/kota, hibah dan sumbangan yang tidak mengikat dari pihak ketiga dan lain-lain pendapatan desa yang sah. Setelah adanya hak anggaran yang dikelola oleh desa, maka muncul kewajiban dari pemerintahan desa dalam proses pembangunan desa. Pembangunan desa bertujuan meningkatkan kesejahteraan masyarakat desa dan kualitas hidup manusia serta penanggulangan kemiskinan melalui pemenuhan kebutuhan dasar, pembangunan sarana dan prasarana desa, pengembangan potensi ekonomi 
Jurnal SOSIO DIALEKTIKA 5 (2) (2020)

P-ISSN: 2540.8941 e-ISSN: 2623.2944

sosiodialektika@unwahas.ac.id
Analisis Pemberdayaan

Masyarakat Desa Dalam

Kemandirian Dan

Pembangunan Di Kecamatan

Jambi Luar Kota

lokal, serta pemanfaatan sumber daya alam dan lingkungan secara berkelanjutan.

Persoalan yang kemudian muncul, apakah dengan anggaran yang di keluarkan oleh negara untuk kemandirian desa dapat diimplementasikan oleh pemerintahan desa guna menunjang program pembangunan desa yang dicanangkan oleh pemerintah pusat. Serta sejauh mana masyarakat ikut terlibat dalam proses pembangunan desa. Oleh karena itu dalam tulisan ini, penulis ingin memberikan sebuah gambaran tentang Analisis Pemberdayaan Masyarakat Desa Dalam Kemandirian Dan Pembangunan Studi Kasus di Kecamatan Jambi Luar Kota.

\section{B. METODE PENELITIAN}

Metode Penelitian yang digunakan dalam penelitian ini adalah kualitatif. Penelitian kualitatif adalah penelitian yang berangkat dari perspektif fokus penelitian yang mengacu pada kualitas makna (Moleong: 2007). Metode pengumpulan data menggunakan penelitian kepustakaan yang didukung oleh media cetak seperti buku, majalah, surat kabar, jurnal, laporan dari berbagai sumber, dan juga media elektronik, terutama internet di mana data merupakan sumber sekunder. Selain data sekunder diatas penulis juga menggunakan data primer yang didapatkan dari wawancara bersama pihak yang kompeten dalam menjawab persoalan penelitian ini. Setelah didapatkan datanya, maka data-data diatas akan dianalisis dalam kerangka teoritis yang telah ditentukan untuk membuktikan bahwa hipotesis itu akurat dan akhirnya dapat menjawab pertanyaan penelitian. Data yang terkumpul dianalisis menggunakan analisis deskriptif untuk lebih mudah dalam menggambarkan Analisis Pemberdayaan Masyarakat Desa Dalam Kemandirian Dan Pembangunan Studi Kasus di Kecamatan Jambi Luar Kota.. Untuk mensistematisasikan data yang dikumpulkan, analisis ini dilakukan melalui beberapa tahapan, yaitu: reduksi data, pemaparan data, deskripsi, dan verifikasi serta menarik kesimpulan. 


\section{HASIL DAN PEMBAHASAN}

Kecamatan Jambi Luar Kota merupakan salah satu dari 11 kecamatan yang ada dalam wilayah Kabupaten Muaro Jambi. Kecamatan Jambi Luar Kota dengan topografi dataran, memiliki luas wilayah $\pm 280 \mathrm{Km} 2$. Kecamatan Jambi Luar Kota terletak diantara 103030'0” BT-1040 0’0” dan $1^{0} 30^{\prime} 0^{\prime}-2^{0} 0$ '0"LS dengan batas-batas wilayah adalah: Utara : Kecamatan Sekernan, Timur : Kecamatan Mestong, Selatan : Kecamatan Kumpeh Ulu, Barat: Kecamatan Pemayung. Wilayah Pemerintahan Kecamatan Jambi Luar Kota terdiri dari 20 desa,53 dusun dan 273 RT. Pusat pemerintahan Kecamatan Jambi Luar Kota terletak di Kel. Pijoan. Jarak Kel. Pijoan ke Ibukota kabupaten kurang lebih $32 \mathrm{Km}$.

\section{Collaborative Governance}

Ansell and gash menjelaskan setrategi baru dari pemerintah disebut sebagai pemerintahan kolaboratif atau collaborative governance. Bentuk dari governace yang melibatkan berbagai stakeholders atau pemangku kepentingan secara bersamaan di dalam sebuah forum dengan aparatur pemerintah untuk membuat keputusan Bersama (Ansell dan Alison, 2007:543). Lebih lanjut menurut Ansel dan Gash, collaborative governance adalah suatu pengaturan pemerintahan dimana satu atau lebih lembaga pubik secara langsung melibatkan para pemangku kepentingan nonpemerintah dalam proses pengambilan keputusan kolektif yang bersifat formal, beroriantasi pada konsensus, dileberaktif yang bertujuan untuk membuat dan menerapkan kebijakan publik serta mengelola aset public.

Collaborative governance menurut Ratner terdapat tiga fokus fase atau tiga tahapan yang merupakan proses kolaborasi dalam tata kelola pemerintahan. (Ratner, 2012:5) dapat dilihat pada gambar berikut ini mengenai permasalahan dan stakeholders lain saling mendengarkan setiap permasalahan yang diterangkan oleh setiap stakeholders yang terlibat. Kemudian memperhitungkan mengenai peluang dalam penyelesaian setiap permasalahan yang telah diidentifikasi, seperti solusi dari permasalahan 
Jurnal SOSIO DIALEKTIKA 5 (2) (2020)

P-ISSN: 2540.8941 e-ISSN: 2623.2944

sosiodialektika@unwahas.ac.id
Analisis Pemberdayaan

Masyarakat Desa Dalam

Kemandirian Dan

Pembangunan Di Kecamatan

Jambi Luar Kota

yang akan terjadi. Setiap stakeholders memiliki kewenangan yang sama dalam menentukan kebijakan pada setiap permasalahan yang telah diidentifikasi dan memperhitungkan peluang berupa achievment yang dapat diperoleh dari masing-masing pihak yang terlibat. Pada dasarnya, fase ini merupakan fase saling mendengarkan mengenai permasalahan dan kesempatan untuk dapat memanfaatkan dari setiap permasalahan yang diterangkan oleh masing-masing stakeholders. Jika dapat kita simpulkan secara lebih sederhana bahwa collaborative governance adalah konsep yang di maknai sebagai kerjasama dalam bentuk interaksi dan kompromi dari pemerintah terhadap masyarakat dan elemen terkait yang secara langsung merasakan akibat dan manfaat. Seperti yang terjadi di kecamatan jambi luar kota pemanfaatan konsep collaborative governance sangat diperlukan guna dapat mendorong elemen elemen masyarakat dapat lebih aktif lagi dalam pembangunan desa menuju pembangunan desa yang mandiri sesuai dengan tuntutan dari pemerintah pusat yaitu membangun kemandirian desa menuju masyarakat yang sejahtera dan mandiri.

\section{Pemberdayaan Masyarakat}

Menurut Adger (2003:9) The Webster \& Oxford English Dictionari dalam pokok-pokok penjelasan mengenai kebijakan pemberdayaan masyarakat dalam rangka kemandirian memberikan dua arti yang berbeda mengenai pemberdayaan sebagai: 1. Memberikan kekuasaan, mengalihkan kekuatan atau menegakkan otoritas kepihak lain sedangkan, 2. Diartikan sebagai upaya untuk memberikan kemampuan dan keberdayaan.

Menurut Koenjaraningrat (2012: 122) masyarakat merupakan kesatuan hidup manusia yang berinteraksi sesuai dengan sistem adat-istiadat tertentu yang sifatnya berkesinambungan dan terikat oleh suatu rasa identitas bersama. Sedangkan Menurut J.L. Gilin dan J.P. Gilin dalam Syani (2012:32), masyarakat merupakan kelompok manusia yang terbesar dan mempunyai kebiasaan, persatuan, sikap dan tradisi yang sama. 


\section{Pembangunan di Kecamatan Jambi Luar Kota}

\section{Pembangunan Sarana dan Prasarana transportasi}

Pembangunan sarana dan prasarana memiliki peran yang sangat penting dalam mendukung aktivitas ekonomi, sosial, budaya, serta kesatuan dan persatuan bangsa terutama sebagai modal dasar dalam memfasilitasi interaksi dan komunikasi di antara kelompok masyarakat serta mengikat dan menghubungkan antarwilayah. Pembangunan sarana dan prasarana, yang menjadi kesatuan dari pembangunan nasional, diharapkan dapat menjadi motor penggerak pertumbuhan perekonomian nasional dan mendukung daya saing nasional secara global. Dalam hal ini lebih ditujukan dalam pembangunan jalan seperti semenisasi agar masyarakat lebih mudah melakukan aktifitas dalam bidang pertanian seperti mengekspor hasil pertanian ke kabupaten/kota.

Adapun pembangunan sarana dan prasarana transportasi di Kecamatan Jambi Luar Kota saat ini sudah banyak dilakukan, namun hasil dari pembangunan yang dilakukan di kecamatan jambi luar kota belum maksimal, hal itu bisa kita lihat dari belum meratanya pembangunan jalan di beberapa desa di kecamatan jambi luar kota. Sedangkan penduduk kecamatan jambi luar kota relatif banyak dan padat. Jika pemerintah desa mampu memaksimalkan potensi Sumber daya manusia yang ada maka pembangunan sarana prasarana transportasi di kecamatan jambi luar kota bisa lebih maksimal lagi.

\section{Pembangunan Sarana dan Prasarana Kesehatan}

Pembangunan kesehatan sebagai bagian integral dari pembangunan nasional menjadi tanggung jawab bersama antara Pemerintah Pusat, Pemerintah Daerah baik Provinsi dan atau Kabupaten/Kota, masyarakat serta dunia usaha dalam rangka mewujudkan derajat kesehatan masyarakat yang setinggi-tingginya. Perkembangan pembangunan kesehatan di Kecamatan Jambi Luar Kota dipengaruhi oleh beberapa faktor diantaranya pemenuhan sarana dan prasarana pelayanan kesehatan menyeluruh yang dekat dengan masyarakat. 
Tabel 1:

Kondisi Sarana dan Prasarana Pelayanan Kesehatan

Kecamatan Jambi Luar Kota

\begin{tabular}{|c|l|c|c|c|c|}
\hline \multirow{2}{*}{ No } & \multirow{2}{*}{ Sarana/Prasarana } & \multirow{2}{*}{ Jumlah } & \multicolumn{3}{|c|}{ Kondisi } \\
\cline { 4 - 6 } & & & Baik & Sedang & Rusak \\
\hline 1 & Puskesmas & 3 & 2 & 1 & - \\
\hline 2 & Posyandu Desa & 75 & 35 & 40 & - \\
\hline 3 & Posbindu & 26 & 10 & 16 & \\
\hline
\end{tabular}

Sumber data : Arsip kantor Kecamatan Jambi Luar Kota

\section{Pemberdayaan Lembaga Kemasyarakatan}

Pemberdayaan masyarakat sebagai proses pembelajaran partisipatif baik secara individu maupun kelompok guna menggerakkan, dan mengembangkan daya serta meningkatkan kemampuan dan kemandirian masyarakat, untuk berbuat bagi dirinya sendiri secara swadaya maupun secara sosial kemasyarakatan yang mencakup upaya peningkatan kondisi sosial, ekonomi maupun kualitas hidup masyarakat. Pemberdayaan masyarakat dilaksanakan melalui program-program dan kegiatan konkrit yang bertumpu pada potensi lokal/daerah, budaya dan tingkat pengetahuan masyarakat serta memperhatikan kompleksitas permasalahan yang terjadi di dalam masyarakat. Sehingga program pemberdayaan masyarakat tersebut tepat sasaran, berdayaguna dan berhasilguna dan ingin terus memberdayakan lembaga-lembaga sosial seperti pkk, karang taruna dan lain sebagai nya agar terciptanya tatanan masyarakat yang berkualitas. Adapun Pemberdayaan lembaga kemasyarakatan di kecamatan jambi luar kota saat ini sudah banyak dilakukan, namun hasilnya belum maksimal dikarenakan masih ada beberapa potensi lembaga kemasyarakatan yang belum di berdayakan seperti karang taruna dan organisasi-organisasi kepemudaan yang lainnya. Hal ini jika benar-benar diberdayakan maka tujuan untuk membangun kemandirian masyarakat desa bisa tercapai seperti membuat 
kegiatan-kegiatan yang produktif bagi pemuda-pemuda di kecamatan jambi luar kota.

\section{Pengembangan Sentra Perekonomian Desa}

Selaras dengan visi pembangunan nasional sebagaimana tertuang dalam Undang- Undang Nomor 17 Tahun 2007 tentang Rencana Pembangunan Jangka Panjang Nasional 2005-2025, maka visi Percepatan dan Perluasan Pembangunan Ekonomi Indonesia adalah "Mewujudkan Masyarakat Indonesia yang Mandiri, Maju, Adil, dan Makmur. Pembangunan dalam bidang perekonomian di keccamatan jambi luar kota akan mendorong investasi di wilayah pedesaan dengan demikian diharapkan akan mampu menciptakan pemerintahan di daerah yang mandiri dan otonom. Beberapa sentra perekonomian yang dibangun di Kecamatan Jambi Luar kota seperti rumah makan dan sektor parawisata. Adapun jumlah restoran/rumah makan di kecamatan jambi luar kota yaitu 156 rumah makan dan beberapa tempat wisata.

Faktor-faktor yang Mempengaruhi Belum maksimalnya pemberdayaan masyarakat dan Pembangunan di Kecamatan Jambi

\section{Luar Kota}

\section{Faktor Komunikasi}

Komunikasi merupakan sebuah proses pertukaran informasi atau pesan. Peran komunikasi sangat penting dalam kehidupan manusia yang pada hakikatnya adalah mahluk sosial. Manusia tidak hidup sendiri dengan pikirannya sendiri. Seseorang perlu melakukan interaksi dengan orang lain, mengkomunikasikan isi pikirannya kepada orang lain. Dalam berkomunikasi, ada banyak faktor yang mempengaruhi jalannya proses komunikasi itu sendiri. Baik faktor internal maupun faktor eksternal komunikator. Faktor-faktor ini akan mempengaruhi baik tidaknya, berhasil atau tidaknya komunikasi yang dilakukan. Menurut Scoot M Cultip (1995), ada banyak faktor yang mempengarui sukses atau gagalnya suatu 
komunikasi. Salah satunya adalah kredibilitas (credibility). Kredibilitas adalah berkaitan dengan hubungan saling percaya antara komunikator dan komunikan. Komunikator perlu memiliki kredibilitas dimata komunikan, misalnya dalam hal tingkat keahliannya dalam bidang yang bersangkutan dengan pesan/ informasi yang disampaikan.

Berdasarkan hasil dari pengamatan tim peneliti, komunikasi yang dijalankan oleh pemerintah desa kecamatan jambi luar kota dengan masyarakatnya belum maksimal. Hal ini terlihat dari komunikasi ditengah masyarakat jambi luar kota yang masih terdapat beberapa perbedaan didalam memahami kebijakan pemerintah desa dan juga ada perbedaanperbedaan dalam pelaksanaan kebijakan antara desa yang satu dengan desa yang lainnya di kecamatan jambi luar kota. Hal ini yang menjadi faktor mengapa pemberdayaan masyarakat desa dan pembangunan di kecamatan jambi luar kota saat ini belum maksimal. Misalnya dalam komunikasi pembangunan pasar di kecamatan jambi luar kota terdapat disparitas antar desa satu dengan yang lainnya.

\section{Gambar 1:}

\section{Jumlah Pasar di Kecamatan Jambi Luar Kota Perdesa/Kelurahan}

\begin{tabular}{|c|c|c|c|}
\hline $\begin{array}{l}\text { Desa/Kelurahan } \\
\text { Villages/Subdistricts }\end{array}$ & $\begin{array}{c}\text { Pasar } \\
\text { Permanen } \\
\text { permanent } \\
\text { Market }\end{array}$ & $\begin{array}{l}\text { Luas } \\
\text { Lahan }\end{array}$ & $\begin{array}{l}\text { Jumlah } \\
\text { Pedangan }\end{array}$ \\
\hline$(1)$ & (2) & (3) & (4) \\
\hline Kel. Pijoan & - & -1 & - \\
\hline Muaro Pijoan & - & - & - \\
\hline Simp. Sei. Duren & - & - & - \\
\hline Sungai Duren & 1 & $200 \mathrm{M} 2$ & 60 \\
\hline Pematang Jering & - & - & - \\
\hline Mendalo Darat & - & - & - \\
\hline Penyengat Olak & - & - & - \\
\hline Senaung & - & - & - \\
\hline Kedemangan & 1 & $2,250 \mathrm{M} 2$ & 114 \\
\hline Rengas Bandung & - & - & - \\
\hline Sembubuk & - & - & - \\
\hline Mendalo Laut & - & - & - \\
\hline Sarang Burung & - & - & - \\
\hline Danau Sarang Elang & 1 & $2.000 \mathrm{M} 2$ & 40 \\
\hline Simpang Limo & - & - & - \\
\hline Sungai Bertam & - & - & - \\
\hline Muhajirin & 1 & $1500 \mathrm{M} 2$ & 181 \\
\hline Maro Sebo & - & - & - \\
\hline Mendalo Indah & - & - & - \\
\hline Pematang Gajah & - & - & - \\
\hline $\begin{array}{l}\text { Jumlah } \\
\text { Total }\end{array}$ & 4 & $5.950 \mathrm{M} 2$ & 395 \\
\hline
\end{tabular}


Jurnal SOSIO DIALEKTIKA 5 (2) (2020)

P-ISSN: 2540.8941 e-ISSN: 2623.2944

sosiodialektika@unwahas.ac.id
Analisis Pemberdayaan

Masyarakat Desa Dalam

Kemandirian Dan

Pembangunan Di Kecamatan

Jambi Luar Kota

Struktur Organisasi

Pemberdayaan masyarakat yang mandiri serta pembangunan desa yang baik sangat ditentukan juga oleh struktur organisasi pemerintahan desa. Karena organisasi pemerintahan desa yang menentukan semua kebijakan yang berkaitan dengan Anggaran Dana Desa di Kecamatan Jambi luar kota. Jika dilihat dari segi struktur organisasi pemerintah desa kecamatan Jambi luar kota saat ini belum bisa dikatakan mencukupi. Pemerintahan desa masih memerlukan sumber daya manusia yang banyak untuk membantu dalam pelaksanaan kegiatan pemberdayaan masyarakat dan pembangunan desa di kecamatan jambi luar kota. Sehingga dengan SDM yang banyak dan berkualitas tadi bisa memaksimalkan dalam memperdayakan masyarakat dan pembangunan yang mandiri di kecamatan jambi luar kota.

Gambar 2:

Struktur Organisasi di Kecamatan Jambi Luar Kota

\begin{tabular}{|c|c|c|c|}
\hline $\begin{array}{l}\text { Nama } \\
\text { Names }\end{array}$ & $\begin{array}{c}\text { NIP } \\
\text { Officer Mains Number }\end{array}$ & $\begin{array}{l}\text { Gol. } \\
\text { Groups }\end{array}$ & $\begin{array}{l}\text { Jabatan } \\
\text { Position }\end{array}$ \\
\hline (1) & (2) & (3) & (4) \\
\hline $\begin{array}{l}\text { Drs. Rossa Candra } \\
\text { Budy.M.Pd }\end{array}$ & 196805131985121002 & N.b & Camat \\
\hline H.lsah, S.Sos.t,M.Ag & 188204022008011004 & HI c & Sekcam \\
\hline Rd.Aman, Sp.d & 186408172007011005 & IIII & Kasi PMD. \\
\hline Poniati & 197110111996022003 & Iito & Staf \\
\hline Budiman & 197108092010011002 & $\mathrm{Hb}$ & Staf \\
\hline Aswan, SAg & 196603121986011002 & Illd & Kasi Trantib \\
\hline Kamardi,SE & 186402021986081006 & Illd & Staf \\
\hline Afriyandi,A.Md & 188301192010011000 & Hd & Staf \\
\hline Reni Hartati,S.Kom & 197710122006042015 & Hile & $\begin{array}{l}\text { Kasubbag } \\
\text { Perencanaan } \\
\text { Kasubbag } \\
\text { Keuangan }\end{array}$ \\
\hline Kristianto Purba,SE & 198805052011011005 & IIIb & Staf \\
\hline Cecep Priyadi & 198403082009011008 & IIIa & Staf \\
\hline Kalduni, SH & 186907062006041005 & Illd & $\begin{array}{l}\text { Kasi } \\
\text { Pemerintahan }\end{array}$ \\
\hline Erman & 196804241893021003 & IIIa & Staf \\
\hline Haramaini & 196302141988031006 & IIIb & Staf \\
\hline Oloan Sani Has buan & 196805172009061003 & Ilb & Staf \\
\hline
\end{tabular}

Sumber: Kantor Kecamatan Jambi Luar Kota

Source : District Office of Jambi Luar Kota 


\begin{tabular}{|c|c|}
\hline $\begin{array}{l}\text { Desa/Kelurahan } \\
\text { Villaged/Subdistricts }\end{array}$ & $\begin{array}{l}\text { Nama Kepala Desa/Kelurahan } \\
\text { Name of Villages/Subdistricts Chief }\end{array}$ \\
\hline (1) & (2) \\
\hline Kel. Pijoan & Susilawati,S.Kom \\
\hline Muaro Pijaan & M.Danl, SE \\
\hline Simp. Sei. Duren & Mulyadi \\
\hline Sungai Duren & Ardiyanto, SE \\
\hline Pematang Jering & A Rasyid \\
\hline Mendalo Darat & Bambarng Santoso \\
\hline Penyengat Olak & Uliya \\
\hline Senaung & Sulaint, S,Sp \\
\hline Kedemangan & Muhammd Bakrie, SE \\
\hline Rengas Bandung & Waono \\
\hline Sembubuk & Sahrudin \\
\hline Mendalo Laut & Ade Irawan \\
\hline Sarang Burung & Idrus, A.Md \\
\hline Danau Sarang Elang & Purwanto \\
\hline Simpang Limo & Jamel \\
\hline Sungai Bertam & Kalduni \\
\hline Muhajirin & Rahmat \\
\hline Maro Sebo & Sutrisno \\
\hline Mendalo Indah & Mustim \\
\hline Pematang Gajah & Drs. H. Rohmat \\
\hline
\end{tabular}

Source : District Office of Jambi Luar Kota

\section{KESIMPULAN}

Sesuai hasil analisis data dan pembahasan sebagaimana yang dikemukakan diatas maka penulis dapat menarik kesimpulan: Dalam hal pembangunan yang telah dilakukan oleh pemerintah kecamatan jambi luar kota yaitu perbaikan jalan, Dalam bidang kesehatan sudah mempunyai puskesmas pembantu dan beberapa posyandu aktif untuk melayani masyarakat di bidang kesehatan, untuk lembaga masyarakat seperti lembaga pemberdayaan masyarakat desa, pkk, karang taruna, adat dan lain sebagainya juga sudah dilakukan. Namun hasilnya belum menunjukkan hasil yang. Dengan demikian, maka harus ada perbaikan untuk kedepannya sehingga apa yang dicitakan oleh pemerintah pusat agar terwujudnya pemerintahan desa mandiri bisa tercapai melalui pemerintah desa dan pada akhirnya terciptanya tatanan masyarakat yang sejahtera dan pembangunan desa yang baik serta mandiri. 


\section{DAFTAR PUSTAKA}

Adisasmita, Raharjo, 2006. Membangun Desa Partisipatif Yogyakarta: Graha Ilmu.

Adger, D. 2003. Core syintax.Oxford, UK: Oxford Univercity Prees.

Budiarjo, Miriam. 2009. Dasar-dasar Ilmu Politik. Jakarta, PT. Gramedia Pustaka Bandung.

Bastian, Indra. 2015. Akuntansi Untuk Kecamatan dan Desa. Jakarta: Erlangga.

Koenjaraningrat.(2012) Pengantar Ilmu Antropologi. Jakartan: Rineka Cipta.

Moleong, J. 2007, Metodelogi Penelitian Kualitatif. Bandung: PT. Remaja Rondakarya Ratner. 2012. Collaborative Governance Assessment. Malaysia: CGIAR.

Riyadi dan Deddy Supriyadi Bratakusumah. 2005. Perencanaan Pembangunan Daerah. Jakarta : PT Gramedia Pustaka Utama.

Sulistyani, Ambar T\& Rosidah. 2003. Manajemen Sumber Daya Manusia : Konsep, Teori dan Pembangunan dalam Konteks Organisasi Publik. Yogyakarta : Graha Ilmu.

Suharto, Edi. 2005, Membangun Masyarakat Memberdayakan Masyarakat. Bandung: PT. Refika Aditama.

Saibani, A dan Djati H. 2014. Pedoman Umum Penyelenggaraan Pemerintah Desa Jilid II Landasan Hukum dan Kelembagaan Pemerintahan Desa. Jakarta: Bee Media Pustaka

Widjaja, Haw. 2005. Otonomi Desa. Jakarta, PT Raja Grafindo Persada.

\section{Jurnal:}

Ansell. Chris, Alison Gash. 2007. Collaborative Governance in Theory and Practice. Volume 18, Issue 4, Journal of Public Administration Research and Theory, University of California: Berkeley.

Mortokusumo, Widjaja. 2011. Contesting the Past: Between Authenticity and Urban Conservation. Volume 10, No 1, ASEAN Journal on Hospitality and Tourism.

\section{Undang-Undang}

Undang-Undang Nomor 23 Tahun 2014 Tentang Pemerintahan Daerah Undang-undang Nomor 6 Tahun 2014 Tentang Desa 